\title{
Milk Marketing Policy Options for the Dairy Industry in New England
}

\author{
M. Doyon, ${ }^{* 1}$ G. Criner, $\dagger$ and L. A. Bragg $\dagger$ \\ *Department of Agricultural Economics and Consumer Science, Laval University, Quebec City, Canada G1K 7P4 \\ †School of Economics, University of Maine, Orono 04469
}

\section{ABSTRACT}

New England dairy farmers are under intense price pressure resulting from important growth in milk production from lower cost of production Southwest states as well as by retailers' market power. Agricultural officials and legislative bodies in New England and in other Northeast US states are aware of these pressures and have been reacting with emergency dairy farm aid, following a very low 2006 milk price, and with state legislations in an attempt to address perceived excess retailing margins for fluid milk. In this paper, we suggest that a sigmoid demand relationship exists for fluid milk. This demand relationship would explain fluid milk asymmetric price transmission, high-low pricing, and the creation of a large retailing margin (chain surplus) often observed for fluid milk. It is also argued that a sigmoid demand relationship offers an opportunity for state legislators to help Northeast dairy farmers capturing a larger share of the dollar of the consumers through various policy options. Therefore, 5 milk market channel regulatory mechanisms (status quo, price gouging, supply control, fair share policy, and chain surplus return) are discussed and compared. The supply control mechanism was found the most effective at redistributing the chain surplus, associated with the sigmoid demand relationship for fluid milk, to dairy farmers. However, this option is unlikely to be politically acceptable in the United States. Second-best options for increasing dairy farmers' share of the consumers' dollar are the fair price policy and the chain surplus return. The former mechanism would distribute the chain surplus between retailers, processors, and farmers, whereas the latter would distribute it between consumers, retailers, and farmers. Remaining mechanisms would either transfer the chain surplus to retailers (status quo) or to consumers (price gouging).

Key words: dairy, policy, retail price, New England

Received September 5, 2007.

Accepted November 29, 2007.

${ }^{1}$ Corresponding author: maurice.doyon@eac.ulaval.ca

\section{INTRODUCTION}

The New England dairy industry is under intense pressure, and its longevity is under question. Physical and economic conditions within the region present distinct disadvantages that cumulatively make it a relatively high production cost region within the United States (Nubern, 1998; Jesse and Jones, 2003). Moreover, New England (New England includes the states of ME, NH, RI, CN, VT, and MA; the Northeast includes New England plus NY, NJ, and PA) has a limited supply of quality farm land, most of which is subject to urban sprawl pressures. For example, Maine has converted more than 850 thousand acres from rural to suburban utilization in the last 2 decades, ranking it second in the nation based upon rural acres lost (Brookings Institute, 2006).

Meanwhile the western United States has rapidly expanded milk production, with the ultimate effect being downward pressure on domestic milk prices. From 1994 to 2004, Southwest US milk and milk fat production increased $44.2 \%$, whereas New England milk and milk fat production decreased $2.0 \%$ (overall US production increased 11.0\%). In 1994, the Southwest accounted for $20.9 \%$ of the US production of milk and milk fat, but by 2004, the percentage of US production in the Southwest had risen to $27.3 \%$. By contrast, New England produced $2.9 \%$ of the milk and milk fat in the nation in 1994 and $2.6 \%$ in 2004 (USDA NASS, 2006). As an example of this east-versus-west phenomena, Figure 1 shows average number of dairy cows per farm for New England vs. New Mexico and Arizona, and Figure 2 shows total dairy cows for New England vs. New Mexico and Arizona. In addition to this production dynamic, Northeast dairy farmers, who rely more heavily on class 1 price than producers in the western US, face what appears to be excess retailing margins for fluid milk (Cotterill, 2006).

Agricultural officials and legislative bodies in New England and in other Northeast US states are aware of these pressures and have been reacting with emergency dairy farm aid, following a very low 2006 milk price, and with state legislations in an attempt to address perceived excess retailing margins for fluid milk. In this 


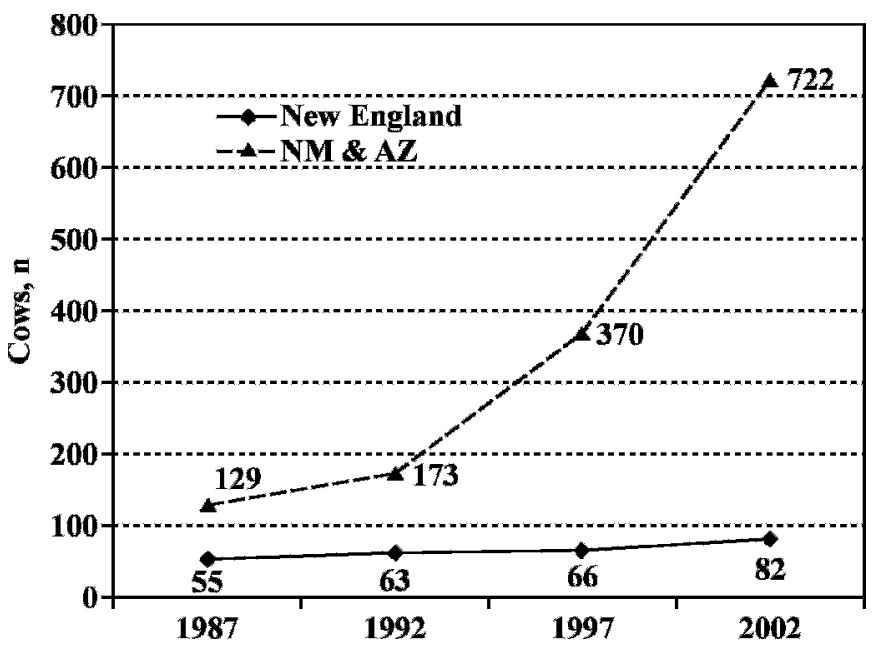

Figure 1. Average number of cows per farm.

paper, we suggest that a sigmoid demand relationship exists for fluid milk. This demand relationship would explain fluid milk asymmetric price transmission, highlow pricing, and the creation of a large retailing margin (chain surplus) often observed for fluid milk. It is also argued that a sigmoid demand relationship offers an opportunity for state legislators to help Northeast dairy farmers capture a larger share of the dollar of consumers through various policy options. Therefore, 5 policy options will be discussed and compared in light of their capability to transfer part of the chain surplus to dairy farmers.

\section{MATERIALS AND METHODS}

\section{Retailing Margins}

We begin this discussion on retailing margins with an example of Maine milk pricing. In Figure 3, average

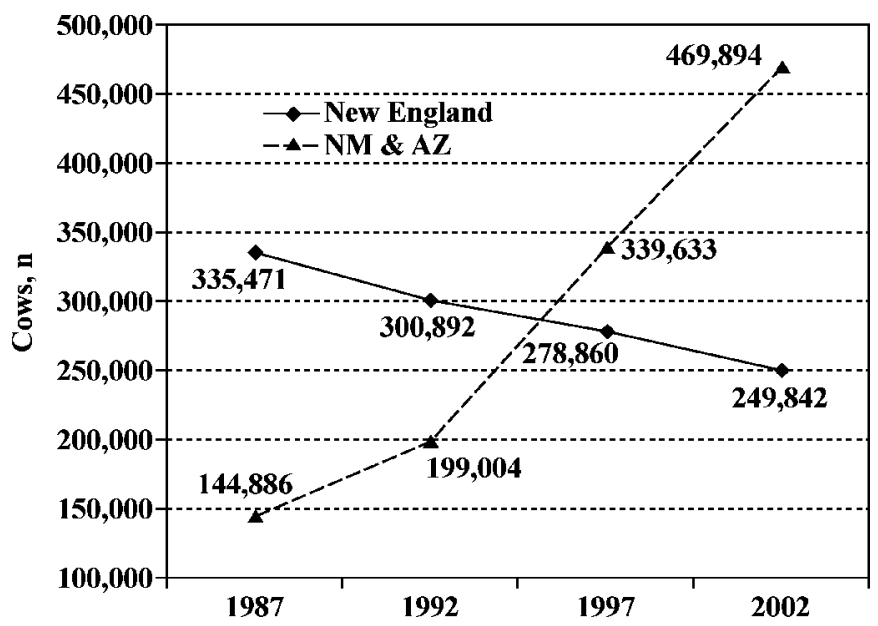

Figure 2. Total number of dairy cows. farm blend price, retail price, and the retail-to-farm margin for fluid milk are shown (Maine Milk Commission, 2006b). The retail-to-farm margin stayed close to $\$ 1.50$ per gallon for essentially 3 yr (2001 to 2003). Milk price volatility led to a high farm-gate price in April 2004. The high April 2004 farm price coupled with the then typical retail-to-farm margin (about $\$ 1.50$ ) resulted in a retail price around $\$ 3.25$. This retail milk price per gallon (\$3.25) was a noticeable jump in price compared with previous years when the price never exceeded $\$ 3.00$. However, although milk price at the farm decreased from mid 2004 to the end of 2005, in Figure 3, no noticeable decreases in retail price were observed. Therefore, the retail-to-farm margin reached $\$ 2.50$ in December 2005 .

To put this farm-retail price spread and chain pricing issue into perspective, some discussion of retailing pricing behavior is needed. Cotterill (2006, p. 243) asserts that "in a competitive market retail prices would tend to follow raw milk prices." This notion of symmetry being required for competitive behavior might be an oversimplification of reality. We know that grocery shoppers weigh the total basket of goods (and services) when selecting which grocery store to select for shopping, whereas retailers seek their own niche combination of products, services, and prices. Li et al. (2006) present several stylized facts regarding the farm-retail spread and retail pricing behavior that support this view. Consider stylized facts 1 and 2 (Li et al., 2006 p. 224):

1. Prices among retailers in a given city for a given commodity exhibit wide dispersion.

2. Retail price changes are at most loosely related to price changes for the farm commodity; thus, acquisition costs play a comparatively minor role in the retail pricing decision.

So what is really going on at retail? Retailers are thought to be generally aware of critical price levels (and price changes), which invoke consumer responses. For example, McLaughlin and Perosio (1994) discuss this phenomenon as it relates to produce retailing in supermarkets. Retailers know that for most items there is a price range within which consumers are rather demand-insensitive. The result is a sigmoid demand relation (Figure 4). Retailers usually know the approximate location of the upper price (Pu), above which consumer demand would significantly drop off. Likewise, they are also aware of the lower price $(\mathbf{P l})$, below which leads to a noticeable jump in quantities purchased.

Based on this model, retailers would be expected to price their product somewhere in the general area of the circle $(\mathrm{Pu})$ or below the area of the triangle $(\mathrm{Pl})$. If 


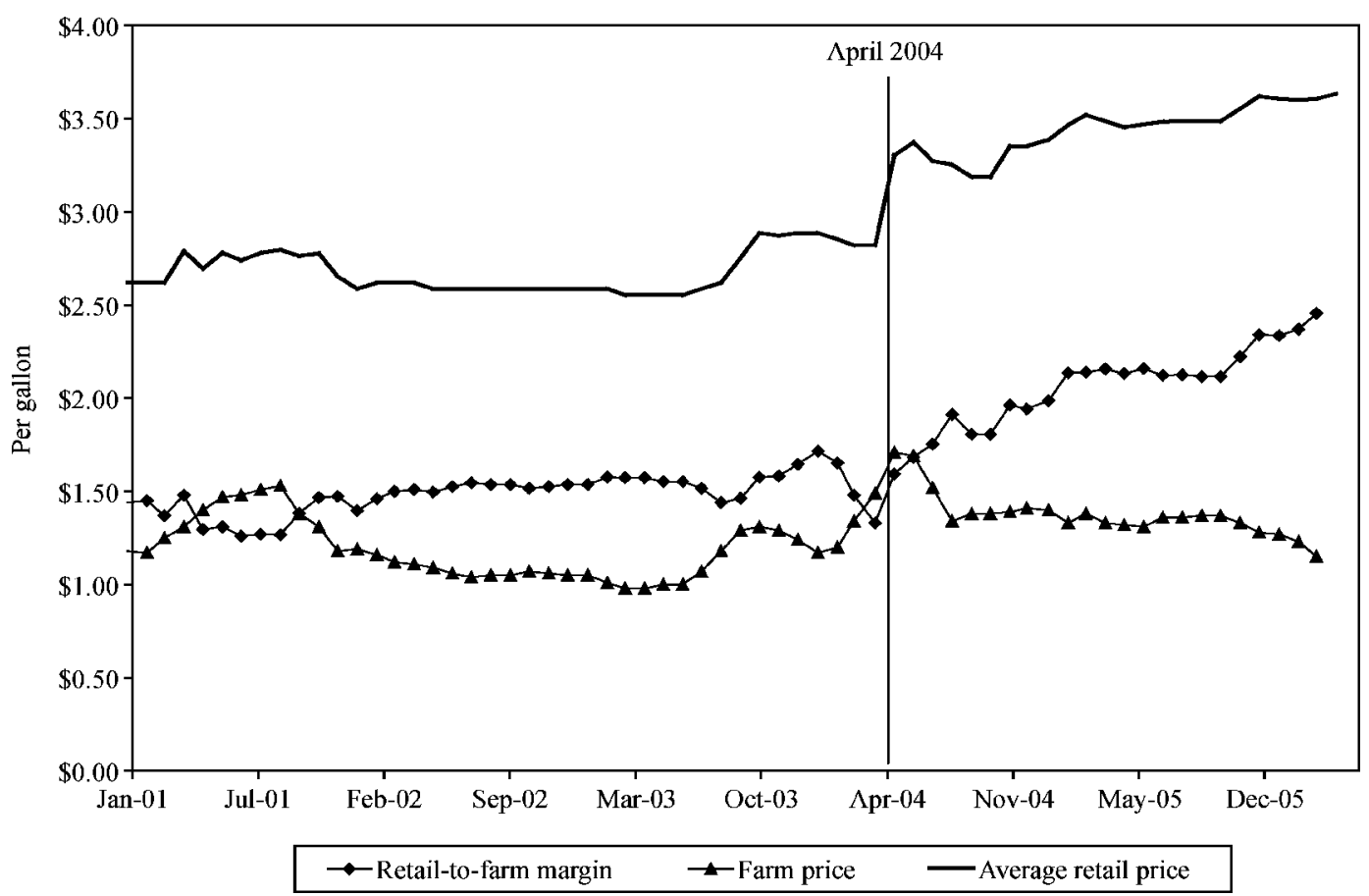

Figure 3. Maine farm price, retail price, and margin for fluid milk (nominal).

retailers charged a price between $\mathrm{Pu}$ and $\mathrm{Pl}$, the result would be a price reduction from $\mathrm{Pu}$ without a significant increase in quantity sold. This is what retailers call giving away margin, which rationally they will not do. However, in not infrequent cases, retailers will drop prices all the way through the insensitive area to a point such as sales price, in which consumers take notice of the price decrease and respond with large purchases. This phenomenon is one rationale for high-low pricing in retailing for produce (Criner et al., 1997).

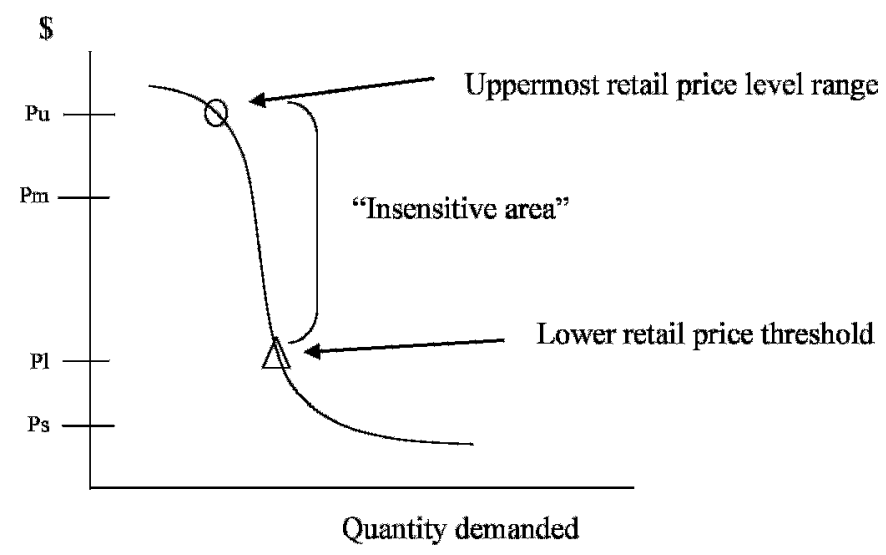

Figure 4. Hypothesized retail demand curve. $\mathrm{Pu}=$ upper price; $\mathrm{Pl}=$ lower price; $\mathrm{Pm}=$ price between $\mathrm{Pu}$ and $\mathrm{Pl} ; \mathrm{Ps}=$ sales price.
Given that Figure 4 can represent fluid milk at retail, stylized fact 2 is no surprise. The sigmoid demand relationship seems appropriate for fluid milk given the inelastic nature of the demand for this product. However, as indicated by Romain et al. (2002), the degree of competition at the retail level will influence retail pricing for fluid milk. Therefore, the capture of a chain surplus from a sigmoid demand would be affected by the local competitive environment of retailers. In fact, within limits, costs of goods to retailers is sometimes not relevant. What is relevant is the upper level of the price threshold represented by $\mathrm{Pu}$ in Figure 4 .

Certainly, when costs of goods increase noticeably, it is in the interest of the retailer to see if the increase can be passed on to the consumers. This is a likely explanation for the general asymmetry observed at retail for fluid milk, in which retailers tend to increase retail price when costs of goods go up but not lower retail prices when costs of goods go down. In fact, Li et al. (2006, p. 226) note that for fluid milk in western cities, price increases were "transmitting more quickly than price decreases." Referring back to Figure 3, the cost of goods increase appears to be a catalyst for a price increase and price searching. The retailers increase their price corresponding to the April 2004 jump in farm price and then seem to search for about 5 mo for a new higher $\mathrm{Pu}$. 


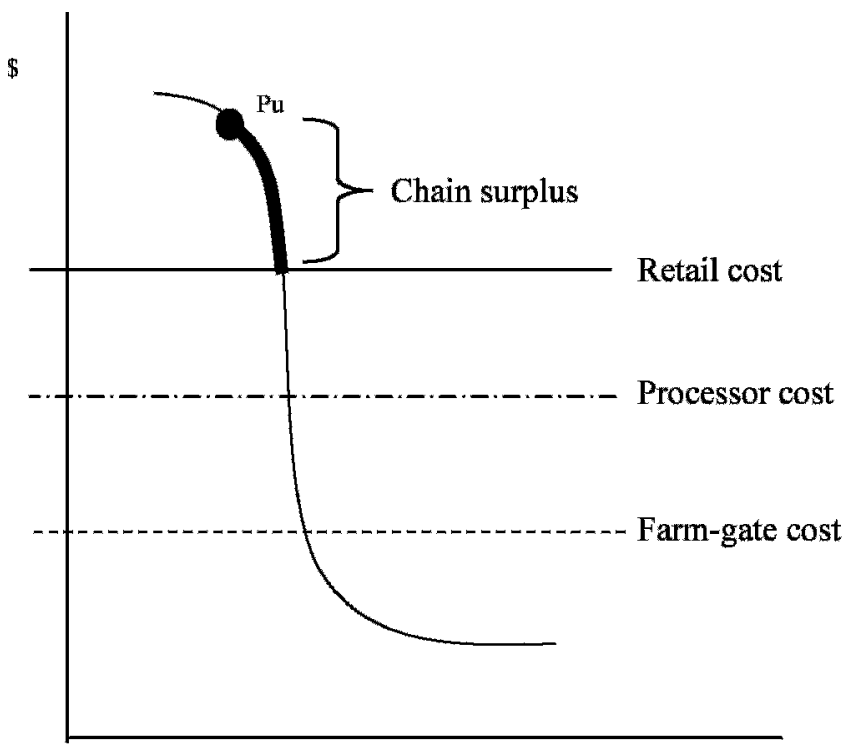

Quantity

Figure 5. Chain pricing. $\mathrm{Pu}=$ upper price.

Figure 5 is presented to introduce the 3 chain levels (farm, processor, and retailer) in relation to the nonlinear demand relationship. We would also argue that it represents the current situation. The lower dashed line represents the farm milk receipts, the distance between the farm cost and the dash-dotted line represents the processor cost, and the distance between the processor cost and the solid line represents the retailing cost. In all 3 cases, the costs hypothetically represent total average costs plus a normal return. When these chain costs sum to a value less than $\mathrm{Pu}$, under the retailing strategy discussed above, the retailer would price at $\mathrm{Pu}$, not at retail cost, unless forced to do otherwise. Thereby, profits are maximized, and the retailer is the main captor of the chain surplus [the chain surplus being defined as the difference between the retail price charged ( $\mathrm{Pu}$ in this case) and the total chain costs (plus a normal return) represented by the retail cost line in Figure 5]. On that issue, Cotterill (2006) asserts that due to market power, retailers are now commanding "stratospheric super-competitive" profit margins.

Thus, the sigmoid demand relationship allows the extraction of a chain surplus, which could be redirected entirely or partially to Northeast dairy farmers to alleviate their economic hardship.

\section{Milk Marketing Policy Tools}

The remainder of this paper will focus on total milk market chain costs for fluid milk and distribution of revenue to the chain participants (farm, processors, and

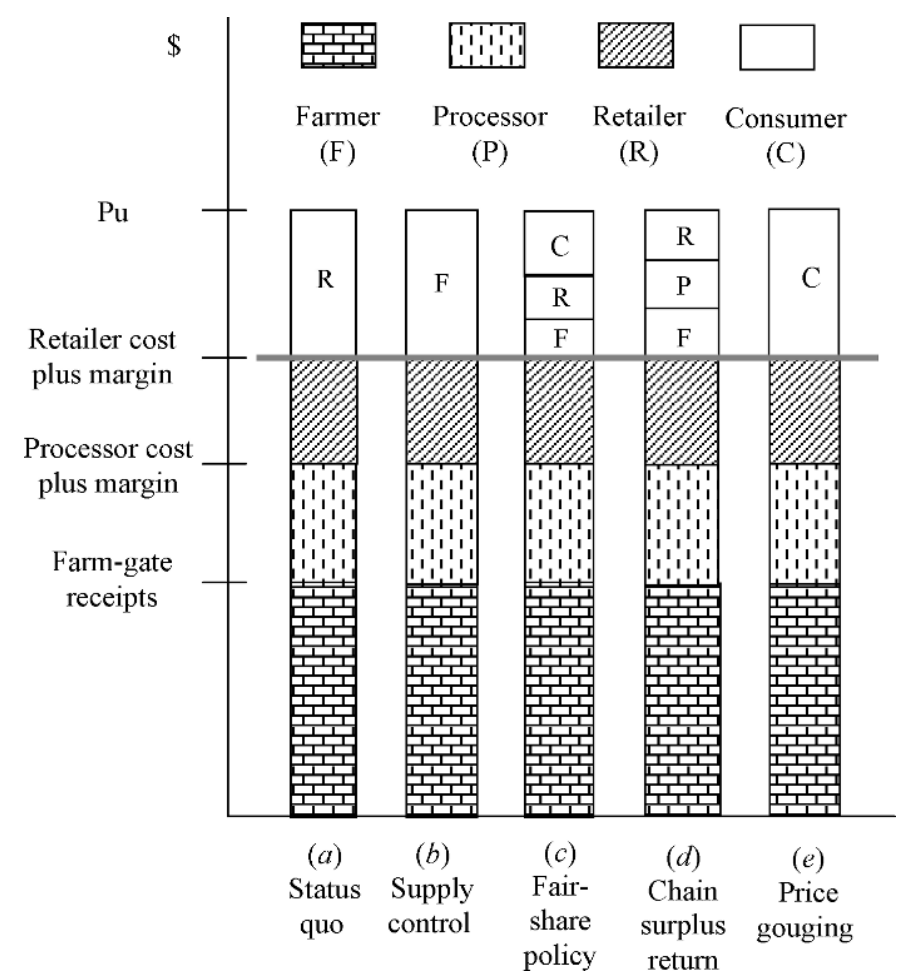

Figure 6. Chain prices under alternative marketing programs. $\mathrm{Pu}=$ upper price.

retailers) through 5 policy options. Each policy has its advantages and disadvantages to the various chain actors as well as varying levels of political acceptance.

In Figure 5, we depicted farm, processor, and retail costs along with the critical price, $\mathrm{Pu}$, which profitmaximizing retailers would be charging customers. Figure 6 links the critical Pu price to block representations for farm, processor, and retailer margins plus the distribution of the chain surplus under the 5 different policy scenarios. The blocks below the gray bar represent margins for the processors and retailers and the blend price for milk plus any premiums received by farms. The boxes above the gray bar represent the chain surplus. The captors of the chain surplus are denoted by a capital letter: $\mathrm{F}=$ farm, $\mathrm{P}=$ processor, $\mathrm{R}=$ retailer, and $\mathrm{C}=$ consumer.

\section{New York Price Gouging}

The New York price gouging law was established to prevent retailers from earning margins on fluid milk that were perceived to be excessive. The catalyst for this was a classic asymmetric pricing case in which farm prices fall and retail prices fall after a significant time lag and often in smaller proportion. The New York legislature passed a gouging law that sets the retail 
price at $200 \%$ of the farm price, including premiums. If a retailer is charging more than the $200 \%$ maximum, New York regulators then check to see whether the allowable retail price is below the estimated costs of retailing milk. In periods of extremely low farm prices, when $200 \%$ of farm price might not cover processor and retailer costs, retailers may use a default $\$ 0.57$ per gallon as a retailing margin. Graphical inspections as well as formal tests have shown that the New York price gouging law has improved price symmetry for the New York City market (Romain et al., 2002).

When the New York price gouging law was passed, there was some expectation or hope that the retailers would continue to charge milk prices at or near what the market would bear (prices like Pu in Figure 5) and that this would buoy the farm price. In effect, the result of the price gouging law was not increased farm prices but rather a lowering of retail prices. Price symmetry was achieved, and consumers gained. In Figure 6, which compares policy effects across the 5 schemes, the price gouging case is represented in column $e$, where chain surplus (the difference between chain costs and the critical price $\mathrm{Pu}$ ), is retained by the consumers.

Upon reflection of the price transmission process, it would have been difficult for the price gouging law to help support farm prices. During times of low farm prices, it would have been in the interest of retailers to pay more for their milk, so long as the farmers received $50 \%$ of the increase. However, the presence of the third chain actor, the processor located between the retailers and farmers, was an impediment to any such price coordination. One can almost imagine retailers telling their milk processor they want to pay them more money, which they want passed back to the farmers. As a whole, this form of regulation is not performing well in terms of returning additional money to farmers or processors, because there is no mechanism for the price gouging law to buoy farm prices. This absence of such a mechanism is addressed in the fair share as well as the chain surplus return regulatory schemes.

\section{Maine Price Minima (the Status Quo)}

Since the 1980s, Maine has sets minimum prices at the producer level and minimum margins at the processor and retailer levels. The Maine Milk Commission (2006a) establishes minimum producer prices, which are normally set at the prevailing southern New England price plus a premium. The Commission also establishes minimum processor and retailer margins based upon periodic cost studies. At one time, the establishment of these minima was seen as essential to prevent predatory retailer and processor price competition, which would put downward pressure on farm prices.
However, these price or margin minima were not designed to have any influence on processor or retailer maximum prices or margins.

At present in Maine and in much of New England, the pricing issue of concern is not predatory pricing but rather the appearance of excessive retailing margins (as shown in Figure 3). However, the minimum pricing system does not cap any prices or margins, nor does it provide any incentive for up-chain actors (retailers and processors) to increase down-chain prices. This case, in which retailers charge what is considered an excessive margin and the regulation has no effect, is presented as the status quo case.

In general terms under the status quo scenario, farmers and processors receive prices equal to some or all of their costs, whereas retailers seek and charge the critical price level $\mathrm{Pu}$. Thus, retailers cover their costs and are also able to capture most of the chain surplus. This is represented in by the horizontal bar in Figure 6 , column $a$, where the area above total chain costs, the chain surplus, accrues to the retailers (denoted by the rectangle labeled $R$ ). This case of retail prices considered to be excessive is the status quo in most of the Northeast, because only New York has a price gouging law at this time.

\section{Quota}

Although the United States has not and would probably never consider the adoption of a formal dairy quota system, the United States has used other supply management programs, such as different herd liquidation programs and the Northeast Dairy Compact (which limited out-of-region milk coming into the Northeast). Thus, quotas are of interest from an economic viewpoint. A supply control program, such as the quota system used in Canada, could theoretically redistribute the chain surplus from the retailers to the farmers. If the quota was set appropriately, the milk supply could be controlled such that farm prices increase to the point in which the addition of the processor and retailer costs bring total chain costs to just equaling $\mathrm{Pu}$. This is shown in column $b$ of Figure 6 . Although farmers would clearly gain from this scenario over the status quo, it would reduce the retail margin to retailing costs and would provide no price benefits to processors or consumers.

\section{Fair Share}

Cotterill (2006) is advocating that New York modify its price gouging law into a fair share law, which would work in the following manner. If the retail margin exceeds $20 \%$ of the cost of the retailer, the excess must be returned to milk producers until their milk return 
equals some level $[\$ 17 / 100 \mathrm{lb}$ or $45.5 \mathrm{~kg}$ (cwt) in his example]. The maximum retail margin that can be charged is $50 \%$. If the prevailing farm price equals the established farm minimum (e.g., $\$ 17 / 100 \mathrm{lb}$ ), then none of the retail margin is redistributed to the farmers, but the 50\% maximum retail margin is maintained.

One can see how the proposed fair share law offers several improvements over the price gouging law. It provides an incentive for retailers to move prices upward when the market can bear it, plus explicitly provides a mechanism for returning money to the farmer. As depicted in column $c$ of Figure 6, retailers would normally gain margin above costs. However, retailers are required to distribute money back to farmers anytime the farm level milk price is below the trigger price (e.g., $\$ 17 / 100 \mathrm{lb}$ ) and the retail margin is above $20 \%$. In addition, the $50 \%$ margin cap on retailers would likely prevent retailers from obtaining the entire chain surplus.

There are, however, some minor drawbacks with the fair share method. First, although this method can potentially return chain surplus to retailers and farmers, there are no provisions to apportion any chain surplus to processors. Second, during periods of very low raw milk prices, this method could require retailers to sell milk at prices below their cost plus their margin. This would likely be a rare event and could be mitigated by keeping an absolute minimum margin default such as the one currently in place under the New York price gouging law. If raw milk prices drop to such a level that $200 \%$ of the farm price is less than chain costs, retailers can charge $\$ 0.57$ above their costs (Huff, 2007).

\section{Chain Surplus Return}

We propose an additional policy option, a chain surplus return. This option is developed in an effort to expand upon policies already discussed. To explain the chain surplus return regulation, the case of Maine and its milk regulatory body, the Maine Milk Commission (2006a), could be used. The Commission would continue to set farm level prices based upon southern New England prices plus a premium. The Commission would also continue to estimate costs of processing and retailing milk. However, instead of using the processing and retailing cost estimates to establish minimum margins, these costs would be used to establish a method for apportionment of the chain surplus to the 3 chain actors. Under the proposed chain surplus return regulation, any revenue collected above total retail costs would have to be apportioned between farmers, processors, and retailers based upon their share of chain costs.

The chain surplus return scheme is visually represented in column $d$ of Figure 6 . This scheme provides retailers an incentive to search out and charge $\mathrm{Pu}$, because they are allowed to keep a portion of what they charge over their costs. The regulatory body would then collect a portion of the chain surplus from the retailer and allocate it to the farmers and processors. The chain surplus would be allocated by the percentage of total chain cost from each chain level. Like the fair share method, this option provides a mechanism for redistributing money within the chain. Unlike the fair share scheme, this scheme results in consumers paying the market price for milk.

Although the chain surplus return scheme requires cost studies for all actors within the chain, this characteristic is not unique to this tool. The current price gouging law relies on a retailing cost study, and the fair share option would need something similar to ensure that retailers were never forced to sell at a loss.

\section{RESULTS AND DISCUSSION}

Table 1 synthesizes the policy options in addition to proposing an effect ranking. Our rankings should be seen as rough indicators and are certainly debatable. More specifically, the rankings reflect the effect of each market regulation on an individual chain actor (along the vertical axis of the table) from an economic perspective. A rank of 1 indicates the most favorable option to that particular actor.

For example, consumers generally will do best under a price gouging law that is similar to the New York state case, because it caps the allowable retail price at $200 \%$ of retail or the margin of the retailers at $\$ 0.57 / \mathrm{gal}$. Only during periods of very high prices could consumers possibly fair worse under this regulation than others. The second-best scenario for consumers is the fair share regulation, because the retailer margin is capped at $50 \%$ of wholesale prices. Three scenarios, the status quo, supply control, and the chain surplus return, are equally poor for the consumers, because all 3 would likely settle on the maximum price the market would bear $(\mathrm{Pu})$.

If the goal is to bolster a struggling sector within the dairy industry, policy selection from the perspective of an individual chain actor is clear. However, if the goal is to bolster or sustain the industry as a whole, factoring in all chain actors, the best choice is not as clear. Given our rankings, there is no policy option that is simultaneously most favorable for all actors. In this case, policy makers will need to search for an optimal solution by weighing the benefits and costs to each of the actors.

Alternatively stated, policy selection should consider individual effects in addition to aggregate effects. For instance, if consumers in New England were to pay $\$ 0.05$ a gallon more than total cost (which would 
Table 1. Economic effect ranking of different policy scenarios ${ }^{1}$

\begin{tabular}{|c|c|c|c|c|}
\hline Policy type & Producer & Processor & Retailer & Consumer \\
\hline Status quo & $\begin{array}{l}\text { Market } \\
\text { (4) }\end{array}$ & $\begin{array}{l}\text { Market } \\
(2)\end{array}$ & $\begin{array}{l}\text { Cost plus all } \\
\text { chain surplus } \\
\text { (1) }\end{array}$ & $\begin{array}{l}\text { Paying maximum } \\
\text { market will bear } \\
\text { (3) }\end{array}$ \\
\hline Fair share & $\begin{array}{l}\text { Market plus portion of } \\
\text { chain surplus with cap } \\
\text { (3) }\end{array}$ & $\begin{array}{l}\text { Market } \\
\text { (2) }\end{array}$ & $\begin{array}{l}\text { Cost plus portion of } \\
\text { chain surplus with cap } \\
\text { (3) }\end{array}$ & $\begin{array}{l}\text { Paying less than market } \\
\text { maximum, more than } \\
\text { chain cost } \\
\text { (2) }\end{array}$ \\
\hline Chain surplus return & $\begin{array}{l}\text { Market plus portion } \\
\text { of chain surplus } \\
\text { (2) }\end{array}$ & $\begin{array}{l}\text { Market plus portion } \\
\text { of chain surplus } \\
\text { (1) }\end{array}$ & $\begin{array}{l}\text { Market plus portion } \\
\text { of chain surplus } \\
\text { (2) }\end{array}$ & $\begin{array}{l}\text { Paying maximum market } \\
\text { will bear } \\
\text { (3) }\end{array}$ \\
\hline Price gouging & $\begin{array}{l}\text { Market } \\
(4)\end{array}$ & $\begin{array}{l}\text { Market } \\
(2)\end{array}$ & $\begin{array}{l}\text { Varies with farm price } \\
( \pm \text { market with floor }) \\
(4)\end{array}$ & $\begin{array}{l}\text { Pay least of all scenarios, } \\
\text { except during high } \\
\text { farm level milk prices } \\
\text { (1) }\end{array}$ \\
\hline
\end{tabular}

\footnotetext{
${ }^{1}$ A ranking of 1 reflects the most favorable scenario for that actor.

${ }^{2}$ For this descriptive analysis, market price or margin is reflective of costs plus a normal return.
}

amount to a price decrease relative to the current price), it would cost a family of three $\$ 3.45$ more a year based on a per-capita consumption of 23 gal a year. However, if that $\$ 0.05$ is captured by dairy farmers, it would represent $\$ 5,300$ in additional annual receipts per farm for each of the 3,050 farms in the New England region.

However, in the longer run, falling food prices, in real terms, will mean that New England dairy farmers will continue to need productivity improvements to remain competitive, even with the implementation of favorable policy measures that would allow them to capture a larger share of the dollar of consumers.

\section{ACKNOWLEDGMENT}

We would like to acknowledge the financial support of Maine Agricultural and Forest Experiment Station (Publication 2991).

\section{REFERENCES}

Brookings Institute. 2006. Charting Maine's Future: An action plan for promoting sustainable prosperity and quality places. http:// www.brookings.edu/reports/2006/10cities.aspx Accessed Oct. $24,2006$.

Cotterill, R. W. 2006. Pricing and policy problems in the Northeast fluid milk industry. Agric. Resour. Econ. Rev. 35:239-250.
Criner, G. K., E. McLaughlin, and A. S. Kezis. 1997. Pricing dynamics in the U.S. fresh produce channels: New empirical evidence. J. Retailing Consum. Serv. 4:259-268.

Huff, C. 2007. Chief, Licensing and Auditing Unit, New York State Department of Agriculture and Markets. Personal interview.

Jesse, E., and B. Jones. (2003). Cost of Production Milk: A Comparison by State. Marketing and Policy Briefing Paper No. 84. Univ. Wisconsin-Madison Extension, WI.

Li, L., R. Sexton, and T. Xia. 2006. Food retailers' pricing and marketing strategies, with implications for producers. Agric. Res. Econ. Rev. 35:221-238.

Maine Milk Commission. 2006a. How Prices are Established. http:// www.maine.gov/agriculture/mmc/priest.htm Accessed Oct. 12, 2006.

Maine Milk Commission. 2006b. Price History Maine Milk Commission Minimum Prices. http://www.maine.gov/agriculture/mmc/ prihis.htm Accessed Oct. 12, 2006.

McLaughlin, E. W., and D. J. Perosio. 1994. Fresh fruit and vegetable procurement dynamics: The role of the supermarket buyer. Research Bulletin 94-1. Dept. Appl. Econ. Manage., Cornell Univ., Ithaca, NY.

Nubern, C. 1998. Cost of Production and its Impact on the Competitiveness of Regional Dairy Industries. US Dairy Markets and Outlook. Vol. 3, no. 3. Dairy Management Inc., Rosemont, IL.

Romain, R., M. Doyon, and M. Frigon. 2002. Effect of state regulations on marketing margins and price transmission asymmetry: Evidence from the New York City and Upstate New York fluid milk market. Agribusiness Int. J. 18:301-316.

USDA, Economic Research Service. 2006. State Fact Sheets. http:// www.ers.usda.gov/statefacts/ Accessed Jan. 27, 2007.

USDA, NASS. 2006. Milk Production, Disposition and Income: 2005 Summary. http://usda.mannlib.cornell.edu/MannUsda/view DocumentInfo.do?docu mentID=1105 Accessed Jan. 27, 2007. 